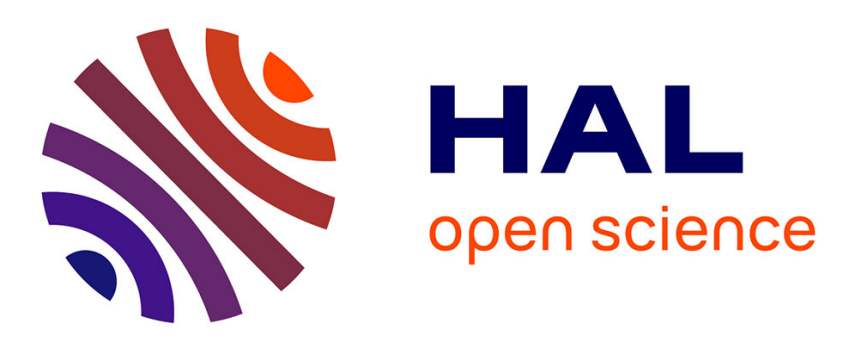

\title{
Influence of the microstructural changes and induced residual stresses on tensile properties of wrought magnesium alloy friction stir welds
}

Loreleï Commin, Myriam Dumont, René Rotinat, Fabrice Pierron, Jean-Eric Masse, Laurent Barrallier

\section{To cite this version:}

Loreleï Commin, Myriam Dumont, René Rotinat, Fabrice Pierron, Jean-Eric Masse, et al.. Influence of the microstructural changes and induced residual stresses on tensile properties of wrought magnesium alloy friction stir welds. Materials Science and Engineering: A, 2012, 551, pp.288-292. 10.1016/j.msea.2012.05.021 . hal-01059258

\section{HAL Id: hal-01059258 https://hal.science/hal-01059258}

Submitted on 29 Aug 2014

HAL is a multi-disciplinary open access archive for the deposit and dissemination of scientific research documents, whether they are published or not. The documents may come from teaching and research institutions in France or abroad, or from public or private research centers.
L'archive ouverte pluridisciplinaire HAL, est destinée au dépôt et à la diffusion de documents scientifiques de niveau recherche, publiés ou non, émanant des établissements d'enseignement et de recherche français ou étrangers, des laboratoires publics ou privés. 


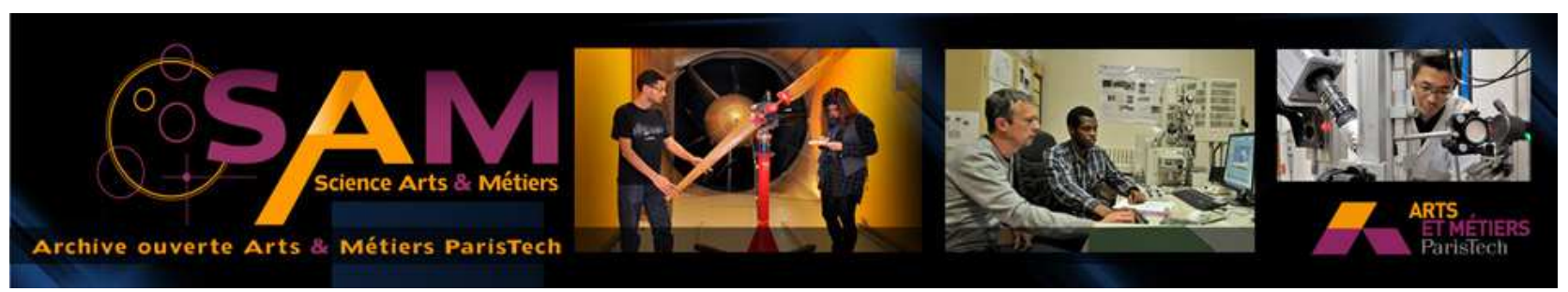

\section{Science Arts \& Métiers (SAM)}

is an open access repository that collects the work of Arts et Métiers ParisTech researchers and makes it freely available over the web where possible.

This is an author-deposited version published in: http://sam.ensam.eu

Handle ID: .http://hdl.handle.net/10985/8412

\section{To cite this version :}

Loreleï COMMIN, Myriam DUMONT, René ROTINAT, Fabrice PIERRON, Jean-Eric MASSE, Laurent BARRALLIER - Influence of the microstructural changes and induced residual stresses on tensile properties of wrought magnesium alloy friction stir welds - Materials Science and Engineering A - Vol. 551, p.288-292 - 2012 


\title{
Influence of the microstructural changes and induced residual stresses on tensile properties of wrought magnesium alloy friction stir welds
}

\author{
Loreleï Commin $^{\mathrm{a}, *}$, Myriam Dumont ${ }^{\mathrm{b}}$, René Rotinat ${ }^{\mathrm{a}}$, Fabrice Pierron ${ }^{\mathrm{a}}$, Jean-Eric Masse ${ }^{\mathrm{c}}$, \\ Laurent Barrallier ${ }^{c}$ \\ a LMPF, Arts et Metiers ParisTech, rue St Dominique, 51000 Châlons en Champagne, France \\ b Aix-Marseille Université, CNRS, IM2NP (UMR 6242), Faculté St-Jérôme, Case 261, Av. Escadrille Normandie-Niemen, 13 397 Marseille Cedex 20, France \\ ${ }^{\mathrm{c}}$ MécaSurf, Arts et Metiers ParisTech, 2 cours des Arts et Métiers, 13100 Aix en Provence, France
}

\section{Keywords:}

Friction stir welding

Magnesium alloys

Speckle interferometry

Residual stress

EBSD

\begin{abstract}
A B S T R A C T
Friction stir welding induces a microstructural evolution and residual stresses that will influence the resulting mechanical properties. Friction stir welds produced from magnesium alloy hot rolled plates were studied. Electron back scattered diffraction was used to determine the texture evolution, residual stresses were analysed using $\mathrm{X}$ ray diffraction and tensile tests coupled with speckle interferometry were performed. The residual stresses induced during friction stir welding present a major influence on the final mechanical properties.
\end{abstract}

\section{Introduction}

Magnesium alloys have raised interest for application in the aircraft industry due to the need of weight reduction. Therefore, developing a reliable joining process for these applications is required, but welding magnesium alloys still faces many challenges [1]. Friction stir welding (FSW) proved to be a process to produce sound welds from magnesium alloy [2-4]. During FSW, the complex thermo-mechanical input results in the microstructure modification in the weld zone and the generation of distinct microstructural areas: the nugget, the thermo-mechanically affected zone (TMAZ), the heat affected zone (HAZ) and the base metal (BM) [2]. Previous studies were mainly focused on the influence of the welding parameters on the resulting tensile properties [5-10]. The microstructural evolution observed during FSW and the residual stresses involved will influence the mechanical properties of the welds [6-12]. It is required then to investigate the mechanisms responsible for the mechanical behaviour evolution consecutive to FSW.

Friction stir welds of AZ31 hot rolled sheet were analysed in this study. A local analysis using a full field measurement technique

\footnotetext{
* Corresponding author. Present address: Karlsruher Institut für Technologie (KIT), IAM-AWP, Hermann-von-Helmholtz-Platz 1, 76344 EggensteinLeopoldshafen, Germany.

E-mail address: lorelei.commin@kit.edu (L. Commin).
}

was performed. It allows the investigation of the contribution of each microstructural area in the mechanical behaviour of the weld. The local texture evolution after FSW was analysed using electron backscattered diffraction (EBSD).

Its influence on the weld mechanical behaviour was compared to the influence of the other microstructural features, such as grain morphology, precipitation state and the influence of residual stress variations.

\section{Experimental procedure}

\subsection{Material and processing}

The base material analysed here is AZ31-O Magnesium alloy. It was supplied by Salzgitter Magnesium Technologies as $2 \mathrm{~mm}$ hot rolled sheets.

Friction stir butt welds were produced with a $5 \mathrm{~mm}$ diameter pin and 2 different shoulder diameters $(10 \mathrm{~mm}$ and $13 \mathrm{~mm})$. The tool rotation rate $(W)$ and the welding speed $(V)$ were kept constant $(W=1000 \mathrm{rpm}, V=200 \mathrm{~mm} / \mathrm{min})$. The applied pressure $(F)$ was in the $6.5-6.8 \mathrm{kN}$ range.

\subsection{Microscopy observations}

Optical microscopy was used to characterise the grain morphology. Electron back scattered diffraction (EBSD) was used to 


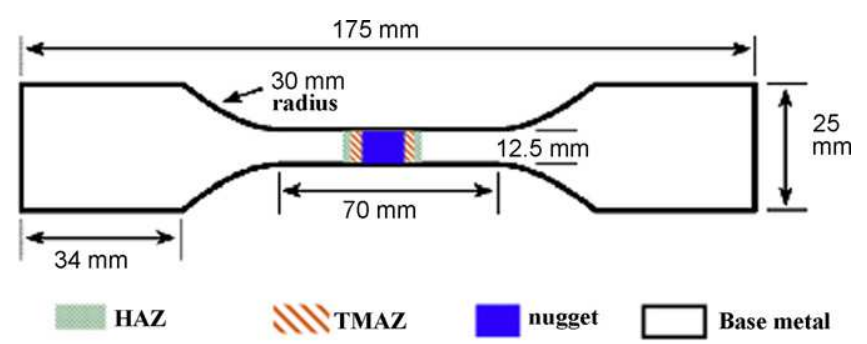

Fig. 1. Tensile specimen geometry.

determine (with a $3^{\circ}$ misorientation angle threshold) texture evolutions.

For optical observations, polished samples were etched with an acetopicral solution $(0.4 \mathrm{~g}$ picric acid, $13 \mathrm{ml}$ ethanol, $3 \mathrm{ml}$ glacier acetic acid and $3 \mathrm{ml}$ boiled water). They were observed using a Leitz Aristomet optical microscope.

For EBSD analysis, a JEOL JMS 6400 scanning electron microscope (SEM) was coupled with an HKL EBSD camera. The samples were mechanically polished using $\mathrm{SiC}$ paper from 400 to 2500 grit and final polishing was performed using a $0.05 \mu \mathrm{m}$ alumina suspension. The etchant solution used for EBSD was $10 \mathrm{ml}$ nitric acid, $30 \mathrm{ml}$ acetic acid, $40 \mathrm{ml}$ boiled water, $120 \mathrm{ml}$ ethanol for $10 \mathrm{~s} \mathrm{[6].} \mathrm{A}$ $20 \mathrm{kV}$ electron beam, $10 \mathrm{nA}$ probe current and a $40 \mathrm{~ms}$ integration time were used.

\subsection{X-ray diffraction}

X-ray diffraction (XRD) was performed using a SEIFERT MZ6TS diffractometer with $\mathrm{Cr} K \alpha$ radiation $(\lambda=0.228975 \mathrm{~nm})$ and a position sensitive detector (PSD). Residual stress profiles across aswelded samples were investigated. The $\{202\}$ diffracting plane and $\sin ^{2} \psi$ analysis method were used [13].

\subsection{Mechanical characterisation}

Conventional tensile tests were performed at $4 \mathrm{~mm} / \mathrm{min}$ strain rate using an Instron 1185 machine with mechanical grips. Five specimens were tested for repeatability. The sample geometry is described in Fig. 1.

To capture the heterogeneity of deformation of the materials, tensile tests were coupled with the speckle interferometry fullfield technique $[14,15]$. The specimen geometry is described in Fig. 2. Speckle interferometry technique allows the in-plane and out-of-plane deformation measurement of an object surface. When a rough surface is illuminated by a beam of coherent light (in practice, a laser beam), this surface reflects the light in all directions according to the principle of Huygens-Fresnel. Speckle patterns are then obtained due to the interference of the back-scattered light.

A Q300 Dantec Ettemeyer speckle interferometry system was used $(1380 \times 1040$ pixels CCD sensor, $2 \times 70 \mathrm{~mW} / 785 \mathrm{~nm}$ wave

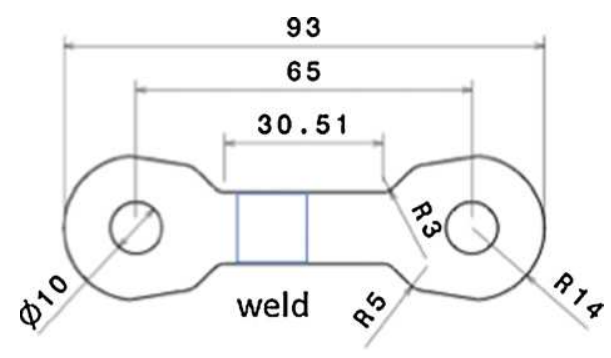

Fig. 2. Geometry of the specimen (dimensions in $\mathrm{mm}$ ).

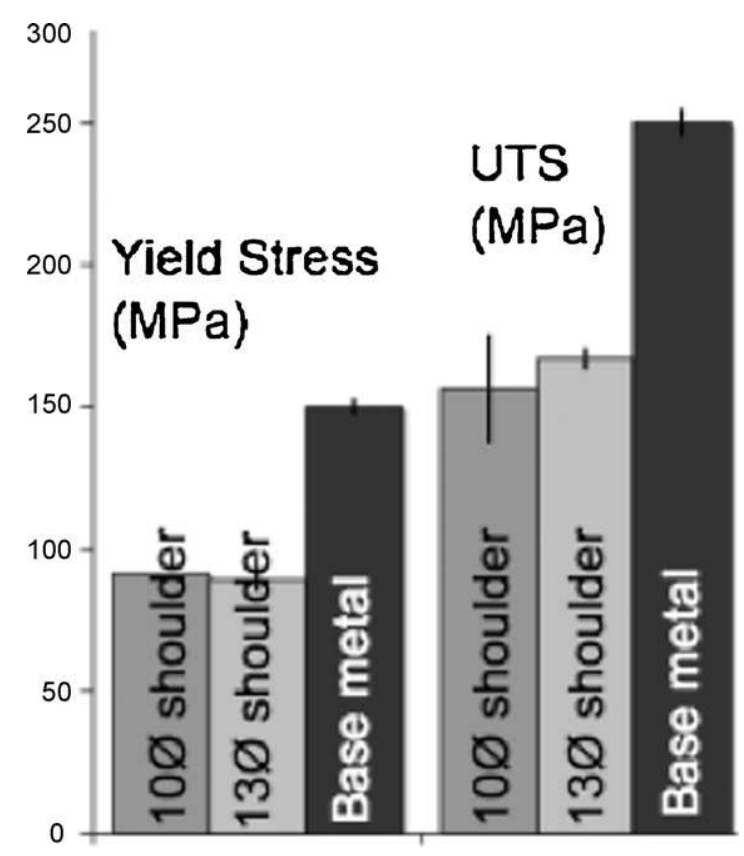

Fig. 3. Tensile properties of the FSW compared to base metal.

length laser diodes, $100 \mathrm{~nm}$ in-plane sensitivity, $30 \mathrm{~nm}$ out-ofplane sensitivity). A layer of diffusive paint was applied to the sample surface to increase diffusive reflection. The test set up consisted of a small in-house developed tensile stage.

The measurement of the phase variation between two speckle images (i.e. steps of loading) allows the calculation of out-of-plane displacement. To measure in-plane displacements, two beams are used. The phase variation gives a first component of in-plane displacement. By using an identical setup rotated by $90^{\circ}$ one obtains the other component of in-plane displacement. The displacement resolution is close to $0.1 \mu \mathrm{m}$ for a spatial resolution of about $16 \mu \mathrm{m}$. Strains were obtained from displacements using a diffuse approximation filtering (radius $=20$ pixels, $248 \mu \mathrm{m}$ resolution) that provides excellent reconstruction/filtering compromise as described in $[16,17]$. The strain resolution is $2 \times 10^{-5}$.

\section{Results}

\subsection{Mechanical behaviour}

As displayed in Fig. 3, FSW butt welds exhibited lower UTS and yield stresses than the base metal.

Speckle interferometry was then used to study the local deformation evolution during tensile testing. A first analysis was performed within the weld through thickness section to investigate the behaviour of each microstructural area. Indeed, it is assumed that the mechanical behaviour is homogeneous along the weld longitudinal direction. The results displayed in Fig. 4 clearly show that strain localisation takes place along the TMAZ. The material had almost undergone no strain in the other areas.

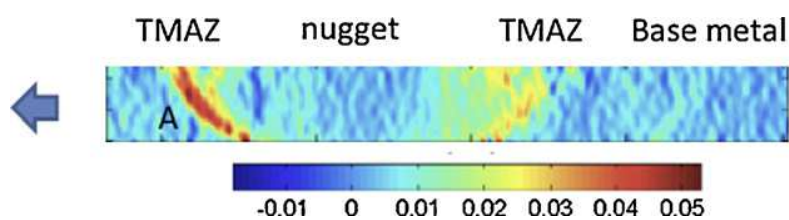

Fig. 4. Speckle deformation map of the sample through-thickness section $(F=2.8 \mathrm{kN})$, the A symbol indicates the advancing side location. 
(a)

(b)

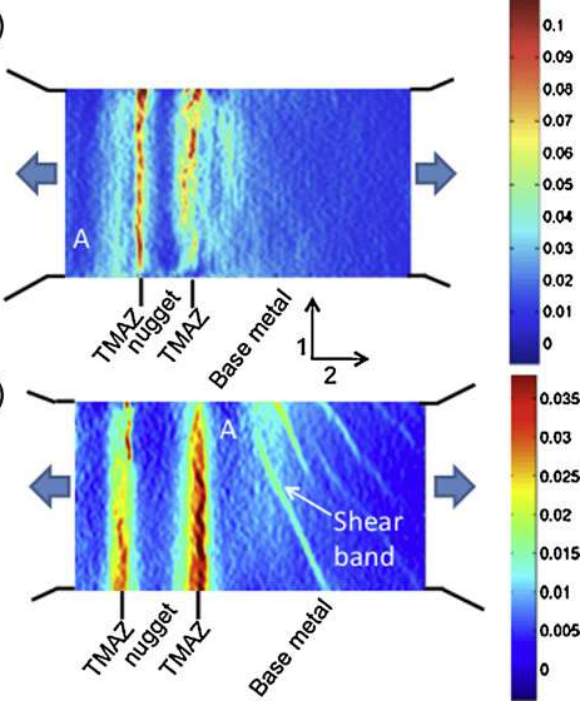

Fig. 5. $\varepsilon_{22}$ Speckle deformation map of the sample top surface for (a) $10 \mathrm{~mm}$ shoulder diameter sample $(F=4.5 \mathrm{kN})$ and (b) $13 \mathrm{~mm}$ shoulder diameter sample $(F=3.5 \mathrm{kN})$, the A symbol indicates the advancing side location for each sample.

Analyses were then performed on the sample top surface to get more measurement points in the analysis window (Fig. 5). The $\varepsilon_{22}$ (tensile longitudinal direction) evolution showed that the strain localisation occurred in the TMAZ area, with higher strains on the advancing side whatever the shoulder size. The shear band formation that was observed in the base metal was already described in [15].

At each step of the tensile loading, a deformation map is measured corresponding to a tensile load applied. From these deformation maps, it can be seen that each part of the sample (associated to a microstructural zone) starts to deform plastically at a different time and therefore at a different applied load. The load measured at the time corresponding to the onset of plastic deformation in the considered part of the sample was used to calculate

$\sigma_{22 \text { localisation }}$

For this calculation, the onset of plastic deformation was chosen at $\varepsilon=0.015$ and the tensile stress was assumed to be uniaxial and homogenous in the test sample thickness (direction 3). Then $\sigma_{22}$ localisation was calculated using the load/cross-section ratio. The results are displayed in Fig. 6.

The analysis of the residual stress distribution across the FSW showed that the highest tensile residual stresses were obtained in the TMAZ (Fig. 6). Using a larger shoulder led to reduce residual stresses. Indeed, increasing the shoulder size resulted in a higher heat input and therefore a thermal expansion mismatch reduction during cooling. This was confirmed by [18] when studying the influence of welding speed, which is also reflecting the heat input, on residual stress generation.

\subsection{Microstructure}

The base metal microstructure consists in fine $10-15 \mu \mathrm{m}$ equiaxed grains (Fig. 7) and intragranular nanoscale precipitation [4]. In our previous study of the FSW weld microstructure, no precipitation evolution was observed [4].

In order to study the influence of the grain size, the shoulder size was varied to generate several nugget grain sizes. Indeed, using a larger shoulder produces higher temperature and promotes grain growth as can be seen on Fig. 7. The local texture evolution was investigated using EBSD. A previous study [7] reported that the shoulder size did not influence the texture modification induced by FSW in the nugget but could weaken the $\{0002\}$ texture in the TMAZ so that fracture could occur in the nugget. The shoulder size did not induce such large modification in our study so that the fracture was still located in the TMAZ. The texture investigation was then performed on the $10 \mathrm{~mm}$ shoulder diameter sample. Fig. 8 shows the IPF (inverse pole figure) map from base metal to nugget. In the base metal, the $\{0002\}$ basal plane normal was parallel to the sample normal direction. This is the typical texture of AZ31 after hot rolling process [12]. Then from the TMAZ to the nugget, progressively the $\left\{\begin{array}{lll}0 & 0 & 2\end{array}\right\}$ basal plane normal aligned to the welding direction.

\section{Discussion}

On the basis of the previous experimental results, the influence of the microstructure (grain size and texture) and the residual stresses on the resulting mechanical properties of AZ31 FSW will be discussed.

\subsection{Influence of the microstructural changes}

Two shoulder sizes were used to study the influence of the grain size on the mechanical behaviour. Indeed, using a small shoulder diameter (i.e. $10 \mathrm{~mm}$ diameter in this study) leads to grain refinement in the nugget whereas with a larger shoulder diameter (i.e. $13 \mathrm{~mm}$ diameter in this study) the resulting grain size in the nugget is similar to the base metal one. Therefore, in the TMAZ, a large grain size gradient is obtained for small shoulder diameter whereas a slight grain size gradient is obtained for large shoulder diameter. Strain localisation and then fracture occurred in the TMAZ for both shoulder sizes. The mechanical properties reached are similar for both welds. Therefore, the grain size

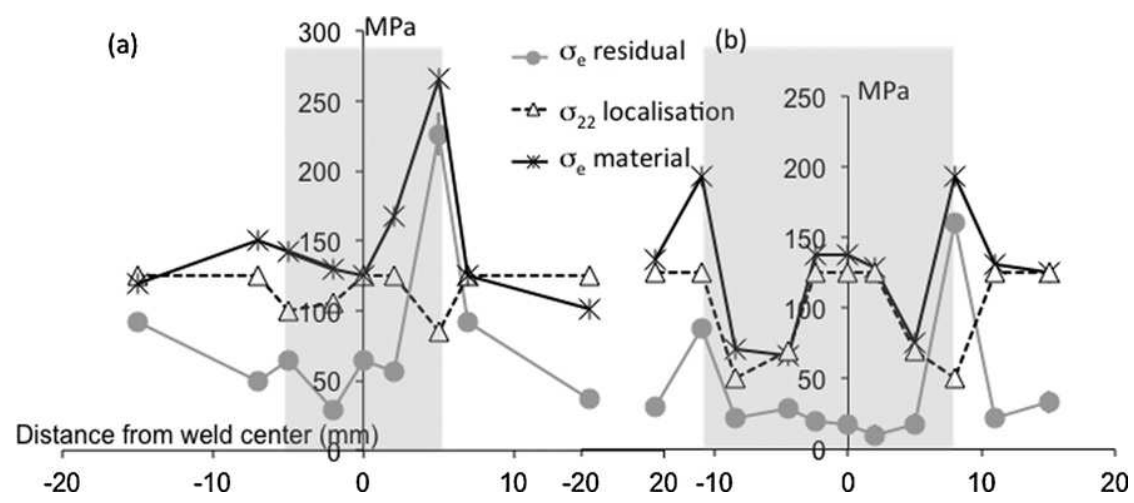

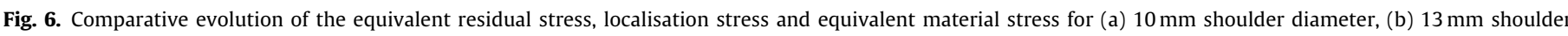
diameter (the shaded area represents the weld zone). 


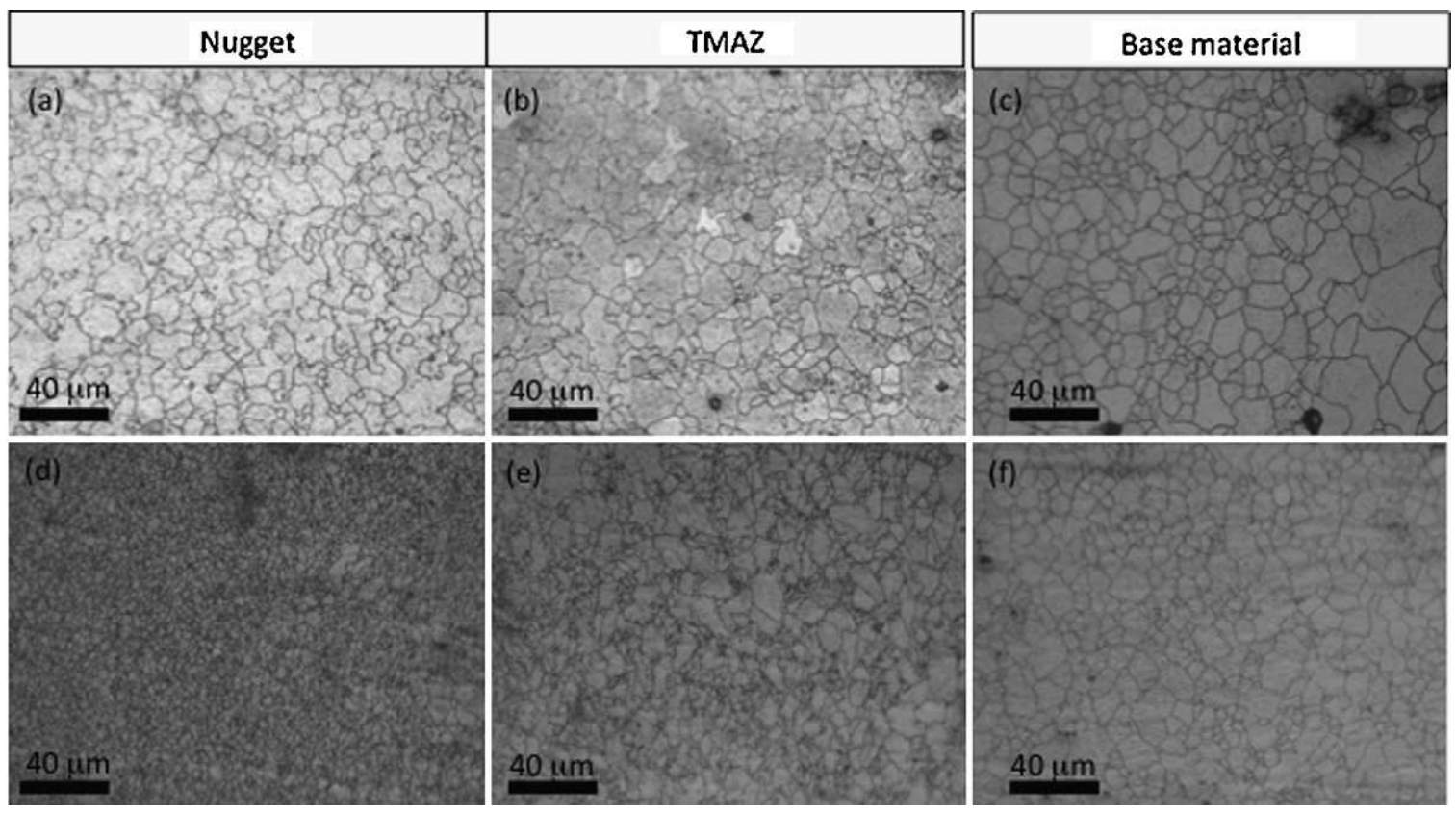

Fig. 7. Grain size evolution with shoulder diameter for $1000 \mathrm{rpm}, 200 \mathrm{~mm} / \mathrm{min}$ butt FSW (a-c) 13 mm shoulder diameter, (d-f) $10 \mathrm{~mm}$ shoulder diameter.

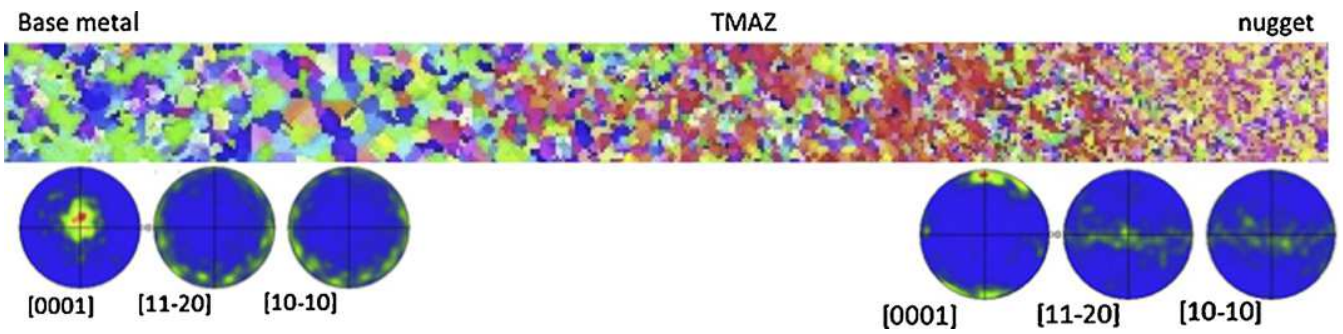

Fig. 8. EBSD analysis across the weld (10 $\mathrm{mm}$ shoulder diameter).

influence is not predominant on the mechanical behaviour. This does not confirm Yang et al. recent study [7] which highlighted that increasing the shoulder size resulted in higher UTS and a fracture location moving from TMAZ to the nugget.

The temperature gradient and the mechanical input induced by the tool pin motion in FSW have a strong effect on the resulting tex-

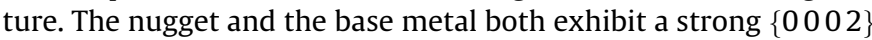
texture but with their basal plane aligned in orthogonal directions. This texture variation is consistent with Woo et al. neutron diffraction experiment [12] and Yang et al. X-ray diffraction experiment [7]. Regarding that the resulting $c$-axis in the base metal and in the nugget are orthogonal to the tensile loading direction, plastic deformation cannot be easily initiated in these regions. In the TMAZ, the grain orientation is less homogeneous thus allowing the deformations to be preferably located in the TMAZ.

\subsection{Influence of the residual stress distribution}

The residual stress state influence on the yield stress evolution can be analysed using $\sigma_{22}$ localisation determined by speckle interferometry and the residual stress tensor calculated in each zone. Indeed, the local material yield stress can be approximated by the equivalent stress (Von Mises) resulting from the residual stress tensor and the tensile localisation stress tensor ( $\left.\sigma_{\text {localisation }}\right)$.

The applied tensile stress is considered as uniaxial whereas the residual stresses are multiaxial. Therefore a tensile stress component corresponding to $\sigma_{22}$ localisation was added to the residual stress corresponding component:

$\sigma_{22}=\sigma_{22(\text { residual })}+\sigma_{22 \text { localisation }}$

with the loading direction, i.e. the weld transverse direction, labelled as direction 2 .

The Von Mises equivalent stress was calculated from the resulting stress tensor, and it was assumed to represent the local material yield stress $\left(\sigma_{\text {e material }}\right)$

Its evolution across the weld was compared to the residual equivalent stress $\left(\sigma_{\mathrm{e} \text { residual }}\right)$ (Fig. 6). An extremely large increase of $\sigma_{\mathrm{e} \text { material }}$ was observed at the advancing side TMAZ. In this area, the residual stresses represent about $80 \%$ of the $\sigma_{\text {e material }}$ (Fig. 6 ).

The same behaviour is observed in the case of samples processed with larger shoulder diameter (Fig. 6). These phenomena can explain the early occurrence of yielding in the TMAZ, which is the result of the combined effect of the texture in that zone and of the high residual stresses introduced by strain gradients during FSW.

\section{Conclusions}

The study of the influence of the microstructure and residual stresses on the mechanical behaviour in AZ31 FSW leads to several conclusions: 
1. FSW samples presented lower yield stress and UTS than AZ31 base metal and the fracture occurred in the advancing side of the TMAZ.

2. The early yielding occurs in the TMAZ, whereas the nugget and base metal zones undergo almost no plastic strains.

3. The strong $\left\{\begin{array}{lll}0 & 0 & 2\end{array}\right\}$ texture of AZ31 hot rolled base metal was modified by the welding process. The basal plane progressively oriented perpendicular to the welding direction when approaching the nugget zone.

4. The texture gradient in the TMAZ localises the deformations in this area.

5. High tensile residual stresses were obtained in the TMAZ, with higher values in the advancing side.

6 . The residual stresses represent a large component in the weld resulting yield strength and therefore residual stresses have a major influence in FSW mechanical behaviour.

\section{Acknowledgements}

This work was performed as a part of AEROMAG Project "Aeronautical Application of Wrought Magnesium" (Project No. AST4-CT-2005-516152) which was supported by the European Union. The authors wish to thank EADS-IW for friction stir welding.

\section{References}

[1] P. Cao, Q. Ma, D.H. St. John, Scripta Mater. 54 (2006) 1853.

[2] R.S. Mishra, Z.Y. Ma, Mater. Sci. Eng. R 50 (2005) 1.

[3] X. Wang, K. Wang, Mater. Sci. Eng. A 431 (2006) 114

[4] L. Commin, M. Dumont, J.E. Masse, L. Barrallier, Acta Mater. 57 (2009) 326.

[5] H.J. Liu, H. Fuji, M. Maeda, K. Nogi, J. Mater. Process. Tech. 143 (2003) 692

[6] N. Afrin, D.L. Chen, X. Cao, M. Jahazi, Mater. Sci. Eng. A 472 (2008) 179.

[7] J. Yang, B.L. Xiao, D. Wang, Z.Y. Ma, Mater. Sci. Eng. A 527 (2010) 708.

[8] S.M. Chowdhury, D.L. Chen, S.D. Bhole, X. Cao, Mater. Sci. Eng. A 527 (2010) 6064.

[9] A. Razal Rose, K. Manisekar, V. Balasubramanian, Trans. Nonferrous Met. Soc. China 21 (2011) 974

[10] D. Liu, H. Nishio, K. Nakata, Mater. Design 32 (2011) 4818.

[11] S.H.C. Park, Y.S. Sato, H. Kokawa, Scripta Mater. 49 (2003) 161.

[12] W. Woo, H. Choo, D.W. Brown, P.K. Liaw, Z. Feng, Scripta Mater. 54 (2006) 1859.

[13] L. Castex, J.L. Lebrun, G. Maeder, J.M. Sprauel, Pub. Sci et Tech. ENSAM, 1981.

[14] L. Commin, M. Dumont, R. Rotinat, F. Pierron, J.E. Masse, L. Barrallier, Mater. Sci. Eng. A 528 (2011) 2049

[15] L. Commin, R. Rotinat, F. Pierron, J.E. Masse, L. Barrallier, Mater. Sci. Technol. 25 (2009) 1215.

[16] B. Nayroles, G. Touzot, P. Villon, Comput. Mech. 10 (1992) 307-318

[17] S. Avril, P. Feissel, F. Pierron, P. Villon, Eur. J. Comput. Mech. 17 (2008) 857-868.

[18] H. Lombard, D.G. Hattingh, A. Steuwer, M.N. James, Mater. Sci. Eng. A 501 (2009) 119 